\title{
Scenario Analysis of Emergency in Civil Aviation Airports Based on the Pressure- State-Response Model and Bayesian Network
}

\author{
Bin Meng ${ }^{1}, \mathrm{Na} \mathrm{Lu}^{1}$, Xinyao Guo ${ }^{1, *}$, Qingmin $\mathrm{Si}^{1}$ and Owen $\mathrm{Bai}^{2}$ \\ ${ }^{1}$ School of Civil Aviation, Zhengzhou University of Aeronautics, Zhengzhou 450046, China \\ ${ }^{2}$ Science Faculty, University College Cork, Cork 999014, Ireland
}

Received 22 June 2020; Accepted 4 September 2020

\begin{abstract}
The emergency response capability of civil aviation airports is the core to ensure the efficient handling of civil aviation emergencies. The dynamic characterization of the multi-scenario evolution paths of emergencies in civil aviation airports and quantitative targeted evaluation have become the study foci urgently needed to be solved by the current academic circles and airport departments for emergency management. To clarify the emergency mechanism, evolution mechanism, and multi-scenario evolution paths, this study first constructed the pressure-state-response (PSR) network expression of emergency scenario evolution in civil aviation airports. Then, the evolution path of airport emergency scenarios and the probability of different evolution scenarios were evaluated on the basis of the PSR model and Bayesian network (BN). Lastly, the specific process of the analysis method for emergency scenarios based on PSR and BN was demonstrated in consideration of emergency rescue drills in civil aviation airports as example. Results show that different emergency response measures are adopted for the critical scenarios of emergencies, and the development and evolution paths of emergency scenarios completely differ. The PSR-BN model for emergency scenario analysis can realize the reasoning process of combining the qualitative and quantitative scenarios of the dynamic evolution of civil aviation emergencies. It can comprehensively and systematically analyse the evolution of emergency scenarios in civil aviation airports, prove the feasibility and effectiveness of the analysis method, and effectively compensate for the shortcomings in the static analysis of emergency events. The model provides reference for the emergency analysis of civil aviation airports.
\end{abstract}

Keywords: Emergency, Scenario analysis, Civil aviation airport, Emergency response, Bayesian network

\section{Introduction}

Air transportation has become the main way for the public to travel. The safety of the civil aviation industry, as a global industry, is closely linked to major social, political, and environmental events, and this industry is susceptible to multiple factors [1]. With increasing complexity of the operating environment in recent years, major civil aviation emergencies, such as severe weather [2], aircraft failure [3], terrorist attacks [4], and bird strikes [5], have been triggered frequently. The emergencies are no longer static and isolated risks but show evident secondary and derivative characteristics, which often lead to the formation of disaster chains, especially some unconventional emergencies; such unconventional emergencies have the characteristics of being difficult to predict and deal with effectively via conventional means, serious disaster consequences, and wide impact range [6]. Therefore, strengthening the level of emergency management has always been a key task of civil aviation industry.

The statistics of The Boeing Company indicated that approximately $75 \%$ of flight accidents in 2009-2018 occurred during the phases of taxi, takeoff, initial climb, final approach, and landing, that is, civil aviation flight accidents mainly occurred in airports and adjacent areas [7]. Therefore, civil aviation airports have become the main body of emergency management and response. As a densely

\footnotetext{
*E-mail address: xyguo@zua.edu.cn

ISSN: $1791-2377$ @ 2020 School of Science, IHU. All rights reserved.

doi:10.25103/iestr. 135.18
}

populated communal public place, a civil airport is also vulnerable to illegal interference, building fire, leakage of dangerous goods, and terrorist attacks. Once an accident occurs, it will lead to high casualties and property losses, resulting in severe social impact and public panic [8]. With increasing diversity, complexity, and coupling of the causes of emergencies, the risk losses and impacts caused by them are increasingly intensified [9]. The emergency management of civil aviation airport involves airlines, air traffic control and other departments, which is difficult to coordinate, complex to handle, and urgent to meet the time requirements. Therefore, determining how to conduct emergency management rapidly and accurately, avoid or reduce the risks caused by certain emergencies, and restore the normal operation of airports immediately has gradually become the focus of the civil aviation industry [10].

Problems, such as the imperfect organization system, the insufficient capability for emergency early warning, and the inadequate linkage among rescue units, are still encountered in the management of civil airport emergencies [11, 12]. On the basis of actual needs, the effective evaluation of the emergency management capacity of civil aviation airports and the establishment of a scientific, reasonable, and efficient evaluation system have become the key links to improve the emergency management level of the entire civil aviation industry. In accordance with the current situation and characteristics of the emergency management in civil aviation and the theory of scenario analysis, this study constructs a scenario description system and a scenario evaluation model of emergencies. They have great 
theoretical and practical significance for improving the emergency management capability of civil aviation airports.

The rest of this study is organized as follows. Section 2 gives the relevant background, including a statement of the management of civil aviation enterprises and the theory of scenario construction. Section 3 presents the analysis theory for emergency scenarios in civil aviation airports is constructed and the theory of PSR model and BN are used to analyze the emergencies in civil aviation airports. The calculation results of the example are analyzed and discussed in Section 4. This study is summarized, and relevant conclusions are drawn in Section 5.

\section{State of the Art}

Annex 19 to the Convention "Safety management" and Doc 9859 "Safety management manual" formulated by the International Civil Aviation Organization proposed that civil aviation enterprises need to formulate emergency response plans and establish coordination mechanisms for emergencies. In particular, civil aviation enterprises should formulate mitigation measures, processes, and control measures through the foreseeable emergency identified by the safety management system (SMS) to solve and reduce the impact of emergencies effectively [13,14]. Risk management focuses on daily risk prevention and control, while emergency management focuses on emergency response and handling; both constitute the SMS as presented in Fig. 1.

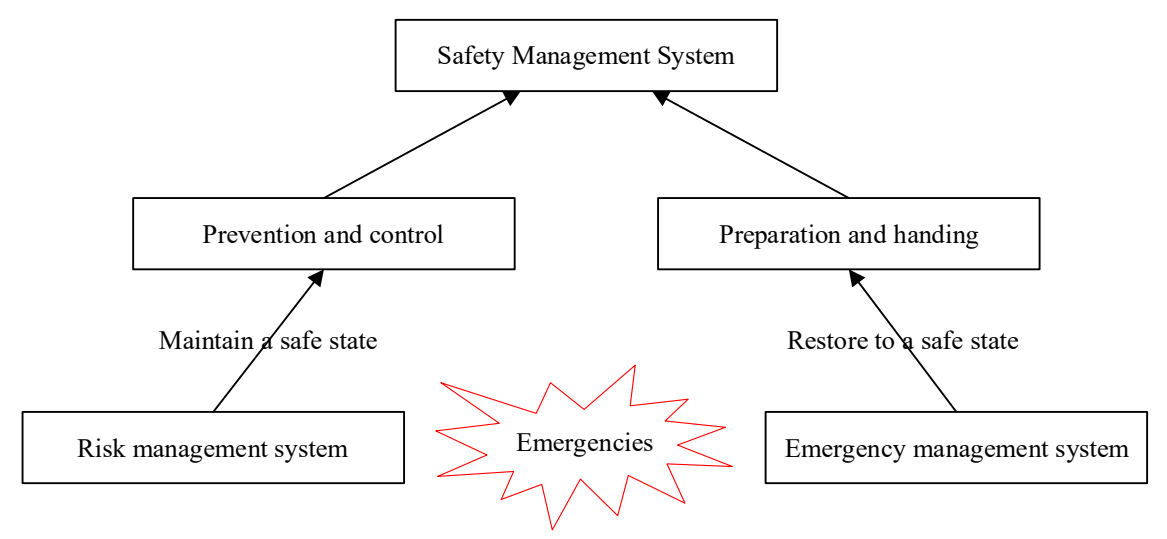

Fig. 1. The roles of risk and emergency management in SMS

Many countries in the world have established a multilevel and complete emergency response mechanism from the perspectives of the government, military, media, and nongovernmental organizations. The study of emergency response mechanisms has reached a quantitative level, and emergency management has been institutionalized [15-17]. Reichardt et al. [18] proposed a risk model for flight operation during a volcanic eruption and emphasized that airlines should promote contingency and drill plans and strengthen flight status and information coordination. Martí Donati [19] simulated the diffusion of volcanic ash in the atmosphere on the basis of a modeling system for volcanic ash and generated an operable short-term forecast to support the emergency management of civil aviation, thereby improving the emergency response speed and reducing the impact of volcanic ash on flights. Xiong et al. [20] used the extended power average operator to provide decisionmaking suggestions for the screening of emergency plans in civil aviation and illustrated the feasibility and effectiveness of the method with a case. Kajko-Mattsson et al. [21] introduced the $\mathrm{CM}^{3}$ model (Emergency Problem Management) to solve the problems on airline emergency software. However, existing studies on the emergency management in civil aviation airports, as the main bearer of emergency management in civil aviation, are insufficiently comprehensive, and numerous studies have been conducted on only one aspect of emergency management in civil aviation airports. For example, Idrose et al. [22] aimed at the study on medical responders for airport disasters. Blackwell et al. [23] conducted a risk assessment for different bird strikes during the approach phase of an aircraft and proposed measures to reduce the risk of bird strikes, such as strengthening the emergency management of airports and increasing bird detection equipment. Manley et al. [24] presented an agent-based model. Several bomb simulation scenarios were conducted at an international airport to determine the influence degree of the environmental change of large and complex structures on the collective behavior and overall evacuation time of passenger groups.

Based on system risk assessment and vulnerability analysis, the analysis method for scenario construction is to describe and assume emergencies from the initial state to multiple possible evolution states in the future. The analysis of the process of scenario change and disaster consequences is of great significance to evaluate the current situation of existing emergency response capability to improve the emergency response capability of the system and reduce its vulnerability $[25,26]$. Emergencies are constantly evolving under the influences of various factors and have the characteristics of coupling, derivation, and complexity; hence, the theory of scenario construction is widely used in emergency management. For example, Zhang [27] extracted the key elements of earthquake emergency management, simulated possible earthquake disaster scenarios by using a scenario construction model, and evaluated them in accordance with actual situations. Liang et al. [28] collated investigation data of major flight accidents to determine their elements and event chains. On the basis of the "scenario-response" method, they constructed the "scenariomission-performance" model for flight emergencies and proved that the model had a practical application value, which could provide a technical reference for emergency works in civil aviation.

In summary, the traditional prediction-response management mode is still mainly used in the field of emergency management in civil aviation airports. Existing study ideas for emergency capacity evaluation are generally to regard emergencies as static risks through establishing 
Bin Meng, Na Lu, Xinyao Guo, Qingmin Si and Owen Bai/

Journal of Engineering Science and Technology Review 13 (5) (2020)143 - 149

relevant indexes, determining their weights, and selecting the average weight or the principle of maximum membership for evaluation. However, for civil aviation airports, especially for some key indexes, this processing method often conceals the impact of the worst indexes on the overall level and could not meet the emergency management needs of unconventional emergencies with complex system characteristics [29]. Therefore, the emergency decision-making paradigm needs to be transformed into a scenario-response type, and the study needs to be further deepened [30, 31]. The analysis of emergency management capacity in civil aviation airports needs to be based on emergency demand scenarios. In view of the shortcomings of existing studies, this study uses the theory of scenario construction to clarify the formation and evolution mechanisms of the emergencies in civil aviation airports. It constructs an analysis technology for emergency scenarios to evaluate the response capacity dynamically on the basis of the theory of pressure-state-response (PSR) model and Bayesian network (BN). It aims to analyze and simulate the process of scenario change and disaster consequences, which can be used as the basis for the study on emergency decision making.

\section{Methodology}

\subsection{Scenario evolution model}

On the basis of existing study results [32-34], this study constructs a scenario evolution model, including disastercausing factors, disaster pregnant environment, disaster carrier, and emergency response. It also introduces the time factors into the process of scenario deduction to discuss the scenario evolution regularity and emergency response effect at key time nodes.

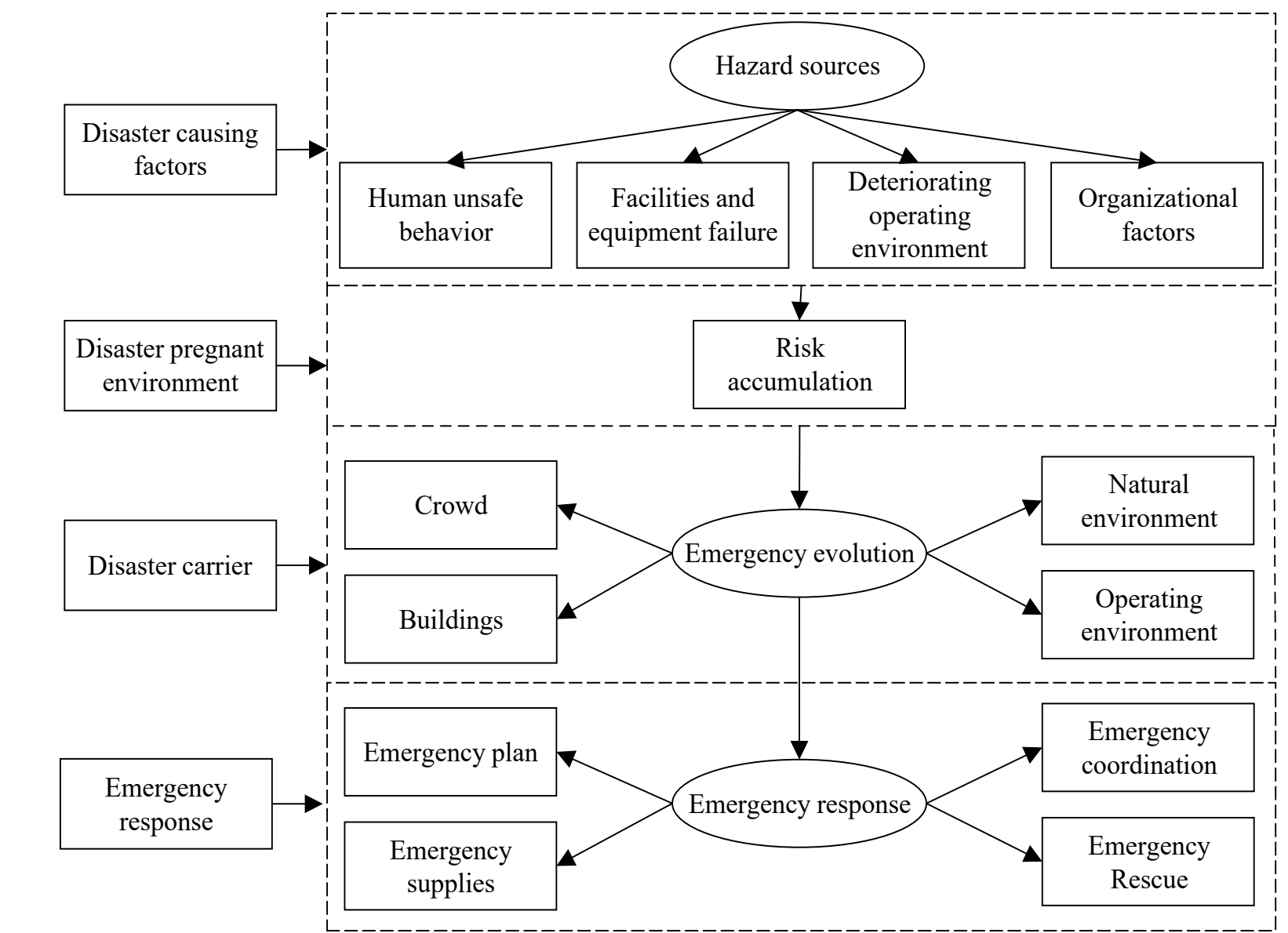

Fig .2. The scenario evolution model for emergencies

\subsection{PSR model}

The PSR model is to describe the evolution process of emergency scenarios by using three scenario elements, namely, "pressure," "state," and "response." The "pressure" index is used to represent all disaster factors from the inside and outside of the system, mainly referring to the disastercausing factors and disaster-preventive environment. The "status" index is used to represent the current damage situation of the system, mainly referring to the disaster carrier. The "response" index is used to represent various emergency response measures implemented to maintain the effective operation of the system, mainly referring to the emergency management. The uses of the indexes are shown in Fig.2

\subsection{BN}

$\mathrm{BN}$ is a tool for system modeling and ratiocination. $S_{1}, S_{2}$, and $S_{3}$ represent three different event nodes; $P\left(S_{3} \mid S_{1}\right)$ and $P\left(S_{3} \mid S_{2}\right)$ represent the probability of occurrence in the case of $S_{1}$ and $S_{2}$; and the directed edge represents the causal relationship among events as presented in Fig. 3. 


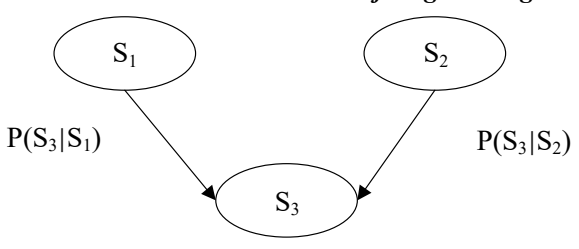

Fig. 3. Bayesian network diagram

$\mathrm{BN}$ uses probability to express the uncertainty of event occurrence, that is, in the case of event $B$, the conditional probability of event $A$ can be expressed as follows:

$$
P(A \mid B)=\frac{P(B \mid A) * P(A)}{P(B)}
$$

\subsection{Steps of the scenario analysis based on PSR and BN}

(1) Representation of emergency scenarios

Each scenario of the emergencies in civil aviation airports can be expressed using the three indexes of "pressure," "state" and "response."

$$
E S_{i}=\left(P_{i}, S_{i}, R_{i}\right)
$$

Where $i$ represents the number of scenarios in the evolution of emergencies; $P_{i}, S_{i}$, and $R_{i}$ represent the scenario elements of "pressure," "state" and "response."

(2) Determination of the content of nodes

A $\mathrm{BN}$ is composed of nodes, which correspond to different emergency scenarios.

The first-level scenario represents the initial scenario of an emergency, which is the starting point of system analysis, expressed by $I S$.

The second-level scenarios, called evolutionary scenarios, which are caused by the evolution of the initial scenario, are represented by the set $(E S, P)$, then

$$
E S=\left(e s_{1}, e s_{2}, \cdots, e s_{m}\right)
$$

Where $e s_{m}$ represents one of the evolutionary scenarios.

$p\left(e s_{m}\right)$ indicates the probability of each scenario, then

$$
\sum_{i=1}^{m} p\left(e s_{m}\right)=1
$$

The third-level scenarios are the disappearance scenarios, that is, the system states after the response to the emergency, which are represented by the set $(E S, P)$, then

$$
F S=\left(f s_{1}, f s_{2}, \cdots f s_{n}\right)
$$

Where $n$ represents the number of disappearance scenarios. $p\left(f s_{n}\right)$ indicates the probability of occurrence of each scenario, then

$$
\sum_{i=1}^{n} p\left(f s_{n}\right)=1
$$

(3) Identification of the relationship among nodes After determining the node content, we need to identify the causal relationship among node scenarios. The development and evolution of emergencies in civil aviation airports are generally from the initial scenario to the evolutionary scenario and finally to the disappearance scenario. In accordance with Fig. 4, the causal relationship among different levels can be determined through the division of the emergency scenario levels.

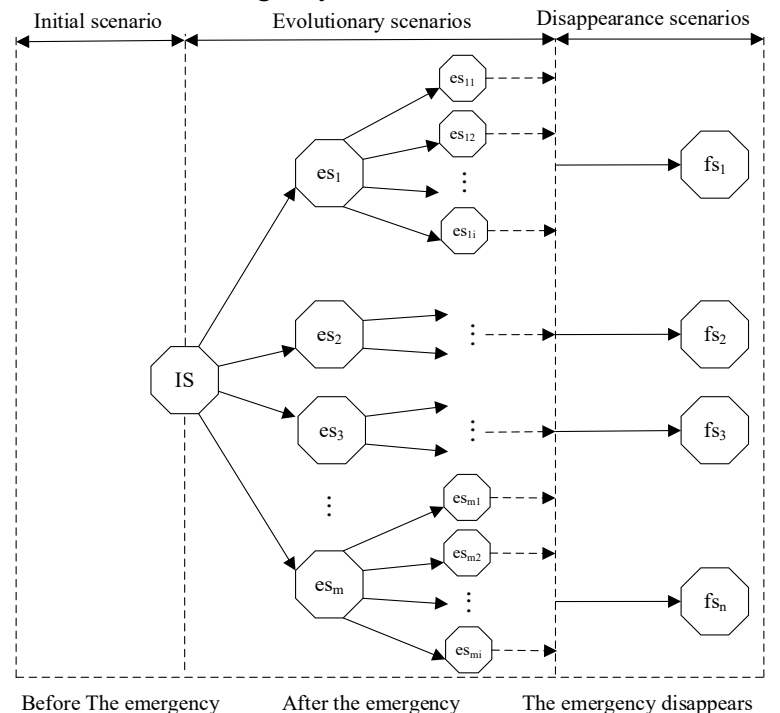

Fig. 4. Scenario evolution sketch of civil aviation airport emergency based on $\mathrm{BN}$

(4) Probability distribution

The scenario analysis of emergencies in civil aviation airports is generally performed after an emergency occurs. The emergency decision-making subject is faced with a real situation that evolves continuously with time and analyzes the present and all possible future evolutionary scenarios of the emergency. Therefore, for the initial scenario without a parent node, the prior probability needs to be specified as $100 \%$, that is, $p(I S)=1$.

For a scenario with a parent node, such as $p\left(e s_{i}\right) \mid p\left(e s_{m}\right)$, the conditional probability is usually assigned by several experts on the basis of their experience.

\section{Results and Discussion}

\subsection{Case description}

This study is based on the case of an emergency rescue drill in an aircraft held in a large airport in China. A brief introduction to the initial scenario of the case is provided as follows. An aircraft encounters a cargo hold fire $2 \mathrm{~min}$ before landing, causing the airport to be closed and the flights to be delayed in a large area. This drill, involving 350 people and nearly 70 vehicles from more than 30 related units, is a relatively large-scale emergency drill activity, which has obtained rich original data and data during the drill.

\subsection{Scenario construction}

The emergency is simplified as follows. During the landing process of a flight, the cargo hold is on fire, then $I S=\left\{P_{I S}, S_{I S}\right\}$, where $P_{I S}$ represents the "pressure" faced from the initial scenario and $S_{I S}$ represents the current "state" of the initial scenario. For the initial scenario $I S$, the emergency management department of the airport can implement different response measures. However, various response measures can cause the initial scenario to develop along different evolutionary paths. 
Hypothesis 1. For the initial scenario $I S=\left\{P_{I S}, S_{I S}\right\}$, if the airport implements the best response measures $R_{f s 1}$, such as conducting rescue operations by the airport fire department and the emergency rescue department without any delay after the aircraft landing, then the fire will be extinguished and passengers on board will be evacuated safely. Therefore, no passenger casualties will occur, resulting in the least number of flight delays. The runway will be reopened after the damaged aircraft is moved. The disappearance scenario $f_{s_{1}}=\left\{P_{f s 1}, S_{f s 1}, R_{f s 1}\right\} \quad$ will be obtained in the end.

Hypothesis 2. For the initial scenario $I S=\left\{P_{I S}, S_{I S}\right\}$, if the response measures $R_{e s 1}$ of the airport are relatively poor and not conducted in time, the passengers on the aircraft will not be evacuated safely and promptly after the aircraft landing, and the fire will spread. This condition will lead to the further evolution of the emergency; secondary disasters, such as increased casualties; and a further increase in the number of airport flight delays. The emergency scenario will develop into an evolutionary scenario $e s_{1}=\left\{P_{e s 1}, S_{e s 1}, R_{e s 1}\right\}$.

Hypothesis 3 . For the evolutionary scenario $e s_{1}$, if the best response measures $R_{f s 2}$ are taken in time, most of passengers will be evacuated safely or the aircraft fire will be extinguished, and the injured passengers will be treated. The runway will reopen after the damaged aircraft has been moved. Then, the disappearance scenario $f_{s_{2}}=\left\{P_{f s 2}, S_{f s 2}, R_{s f 2}\right\}$ will be obtained in the end.

Hypothesis 4. For the evolutionary scenario $e s_{1}$, if the response measures $R_{e s 2}$ are minimally effective, such as the passengers on the aircraft have not yet completely evacuated and the fire has spread further, the emergency will lead to the aircraft explosion, many passenger casualties, and considerable airport flight delays. Then, the emergency scenario will further develop into the evolutionary scenario $e s_{2}=\left\{P_{e s 2}, S_{e s 2}, R_{e s 2}\right\}$. After a long time of disposal, the disappearance scenario $f_{s_{3}}=\left\{P_{f_{s} 3}, S_{f s 3}, R_{s f 3}\right\}$ will be obtained in the end.

The BN structure of the emergency scenario evolution in view of the abovementioned hypotheses is shown in Fig. 5.

\subsection{Determination and calculation of node probabilities} Multiple "response" measures can be implemented for the same scenario, and numerous paths exist for scenario development and evolution. For simplicity, the best "response" ( $\left.R_{f s}\right)$ and the worst "response" $\left(R_{e s}\right)$ are assumed to be implemented for the same scenario. Each scenario has two discrete states: true and false. When constructing the $\mathrm{BN}$, the probability of occurrence and nonoccurrence of each scenario should be input. This study presents the emergency management level of the airport and the development, evolution, and emergency handling of the incidents during the drill to five experts. In accordance with the evaluation results of the five experts, the average value is obtained to specify the conditional probability of each node, as shown in Table. 1.

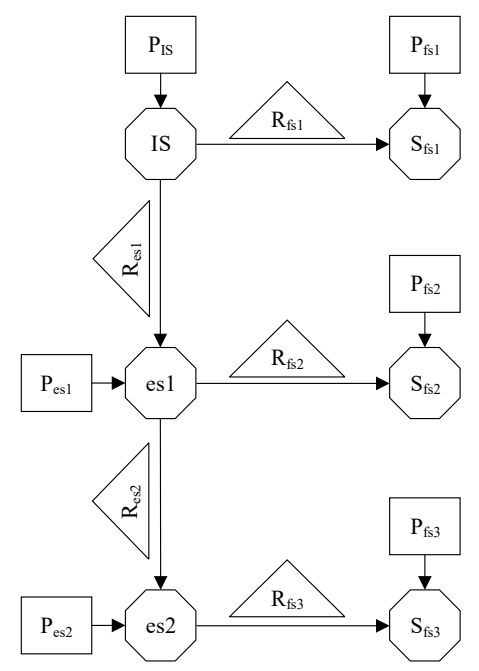

Fig. 5. Scenario evolution sketch of accident based on PSR and BN

From the top of Fig. 3 and in accordance with Eq. (6) in Section 3, the state probabilities of several key scenarios in the evolution process of the emergency can be obtained, as shown in Table 2.

\subsection{Case results}

On the basis of Tables 1 and 2, the result analysis presents the following results:

(1) For the key scenarios of the emergency, different measures are implemented, and the development and evolution paths completely differ.

(2) The occurrence probabilities of the evolutionary scenarios $P\left(e s_{1} \mid I S=\right.$ Ture $)$ and $P\left(e s_{2} \mid e s_{1}=\right.$ Ture $)$ are 0.76 and 0.4656 , respectively. These values indicate that regardless of the implemented response measures, the emergency may continue to evolve. The emergency command center of the civil aviation airport needs to be prepared as soon as possible to meet the next crisis scenario and control the further deterioration of the emergency as much as possible.

(3) The occurrence probabilities of the disappearance scenarios $f s_{1}$ and $f s_{2}$ are 0.65 and 0.6640 , respectively, indicating that the emergency is difficult to predict, evolves rapidly, and is difficult to dispose effectively via conventional means. The emergency has extremely high requirements for the emergency response capability of the civil aviation airport, and the response time is extremely urgent. The disappearance scenario $f_{s_{2}}$ has a relatively high probability, implying the best time to resolve the emergency. If the civil aviation airport can seize this opportunity and take the most appropriate response measures, the emergency is most likely to ease and disappear within a relatively short period of time.

Table 1. Conditional probability table of the accident key scenarios

\begin{tabular}{|c|c|c|c|c|c|}
\hline \multicolumn{3}{|l|}{$I S=\left\{P_{I S}, S_{I S}\right\}$} & $f_{S l}=\left\{P_{f s l}, S_{f s l}, R_{f s l}\right\}$ & $I S=$ Ture & $I S=$ False \\
\hline Ture & 1 & & Ture & 0.65 & 0 \\
\hline False & 0 & & False & 0.35 & 1 \\
\hline$e S_{I}=\left\{P_{e s 1}, S_{e s 1}, R_{e s 1}\right\}$ & IS = Ture & $I S=$ False & $f_{S_{2}}=\left\{P_{f s 2}, S_{f s 2}, R_{f s 2}\right\}$ & $e s_{1}=$ Ture & $e s_{1}=$ False \\
\hline $\begin{array}{l}\text { Ture } \\
\text { False }\end{array}$ & $\begin{array}{l}0.76 \\
0.24\end{array}$ & $\begin{array}{l}0 \\
1\end{array}$ & $\begin{array}{l}\text { Ture } \\
\text { False }\end{array}$ & $\begin{array}{l}0.82 \\
0.18\end{array}$ & $\begin{array}{l}0.17 \\
0.83\end{array}$ \\
\hline
\end{tabular}


Bin Meng, Na Lu, Xinyao Guo, Qingmin Si and Owen Bai/

Journal of Engineering Science and Technology Review 13 (5) (2020)143 - 149

\begin{tabular}{l|l|l|l|l|l}
\hline es $2=\left\{P_{e s 2}, S_{e s 2}, R_{e s 2}\right\}$ & es $1=$ Ture & es $1=$ False & $f_{S 3}=\left\{P_{f s}, S_{f s}, R_{f s}\right\}$ & es $2=$ Ture \\
\hline Ture & 0.38 & 0.23 & Ture & 1 \\
False & 0.62 & 0.77 & False & 0 & 0 \\
\hline
\end{tabular}

Table 2. State probability table of the accident key scenarios

\begin{tabular}{|c|c|c|c|}
\hline \multicolumn{2}{|l|}{$I S=\left\{P_{I S}, S_{I S}\right\}$} & \multicolumn{2}{|c|}{$f_{s_{l}}=\left\{P_{f s l}, S_{f s l}, R_{f s l}\right\}$} \\
\hline Ture & 1 & Ture & 0.65 \\
\hline False & 0 & False & 0.35 \\
\hline \multicolumn{2}{|c|}{$e s_{1}=\left\{P_{e s 1}, S_{e s 1}, R_{e s 1}\right\}$} & \multicolumn{2}{|c|}{$f_{s_{2}}=\left\{P_{f s 2}, S_{f s 2}, R_{f s 2}\right\}$} \\
\hline Ture & 0.76 & Ture & 0.6640 \\
\hline False & 0.24 & False & 0.3360 \\
\hline \multicolumn{2}{|c|}{$e s 2=\left\{P_{e s 2}, S_{e s 2}, R_{e s 2}\right\}$} & \multicolumn{2}{|c|}{$f_{s 3}=\left\{P_{f s 3}, S_{f s}, R_{f s}\right\}$} \\
\hline Ture & 0.4656 & Ture & 0.4656 \\
\hline False & 0.5344 & False & 0.5344 \\
\hline
\end{tabular}

(4) The reasoning result of the model is basically consistent with the scenario evolution of the emergency drill in the large airport. This result proves that the analysis method for emergency scenarios based on the PSR model and $\mathrm{BN}$ is feasible and effective.

\section{Conclusions}

The present characteristics, such as coupling, complexity, and derivation, of emergencies in civil aviation airports make the traditional "prediction-response" decision-making paradigm difficult to apply. The "scenario-response" decision-making paradigm should be adopted to make realtime judgments and decisions on specific emergency scenarios. In this study, the PSR model was used to evaluate the network expression of emergency scenarios in civil aviation airports. Then the steps of building a BN for scenario analysis were proposed and the process of scenario analysis with a specific example was demonstrated. The following conclusions were obtained in this study.

(1) On the basis of the PSR-BN scenario analysis model, the emergency scenarios in civil aviation airports can be defined, and the evolution paths of emergency scenarios and the probabilities of different evolutionary scenarios can be obtained. For the key scenarios of an emergency, if different emergency measures are implemented, the development and evolution paths of the emergency scenario completely differ. The model can effectively compensate for the lack of static evaluation of the emergency capability, which provides a new idea and method for emergency analysis in civil aviation airports.

(2) The scenario analysis method emphasizes to "prepare for the worst case," which can intuitively reflect the "bucket effect" of different evolution scenarios for the emergency response capability of civil aviation airports. This study describes and scientifically assumes an emergency in civil aviation airports from the initial state to various possible future evolution states through example analysis. The objectives are to analyze and simulate the process of scenario change and disaster consequences, evaluate the current situation of the existing emergency capacity of civil aviation airports under different scenarios, and improve the emergency response capacity. This study can be used as a basis for real-time judgments and decisions on specific emergency scenarios.

In sum, on the basis of the PSR-BN scenario analysis model, the emergencies in civil aviation airports can be comprehensively described, and the reasoning combining qualitative and quantitative analyses of different dynamic evolution scenarios can be achieved. However, for the emergency scenarios in civil aviation airports, the amount of information is large, and the scenario description is extremely rich. Thus, the model should be further optimized. On the basis of the current study, a further study will build a scenario database through scenario analysis of emergency rescue cases and plans in civil aviation airports to provide a scientific reference for the evolution trend of emergencies.

\section{Acknowledgements}

This work was supported by humanity and social science youth foundation of ministry of education of China (17YJC630124); Key scientific research projects of colleges and universities of Henan Province in China (17A630069); Key technology projects for the prevention and control of serious and especially serious accidents in safety production (henan-0012-2017AQ); Science and technology planning project of Henan Province in China (202102310624).

This is an Open Access article distributed under the terms of the Creative Commons Attribution License

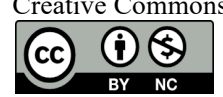

\section{References}

1. International Civil Aviation Organization. "Effects of Novel Coronavirus (COVID-19) on civil aviation: economic impact analysis" [EB/OL]. Retrieved from https://www.icao.int/sustainability/Documents/COVID$19 / \mathrm{ICAO} \% 20$

Coronavirus\%202020\%2003\%2024\%20Econ\%20Impact.pdf, 2020-03-24/2020-04-25.

2. Gultepe, I., Sharman, R., Williams, P. D., Zhou, B., "A review of high impact weather for aviation meteorology". Pure and Applied Geophysics, 176(5), 2019, pp.1869-1921.

3. Huang, C.Y., "Further improving general aviation flight safety: analysis of aircraft accidents during takeoff". Collegiate Aviation Review International, 38(1), 2020, pp.88-105.
4. Al-Saad, S., Ababneh, A., Alazaizeh, M, "The influence of airport security procedures on the intention to re-travel". European Journal of Tourism Research, 23, 2019, pp.127-141.

5. Lee, J. R., Huh, G., "A study on measures enhancing pilots' aeronautical decision making (ADM) competence to prevent bird strike incidents". Journal of the Korean Society for Aviation and Aeronautics, 27(2), 2019, pp.16-25.

6. Rake, E. L., "Emergency management and decision making on accident scenes: taxonomy, models and future research". International Journal of Emergency Management, 1(4), 2003, pp.397-409. 
Bin Meng, Na Lu, Xinyao Guo, Qingmin Si and Owen Bai/

Journal of Engineering Science and Technology Review 13 (5) (2020)143 - 149

7. Boeing. "Statistical Summary of Commercial Jet Airplane Accidents" [EB/OL]. Retrieved from http:/www.boeing.com/resources/boeingdotcom/company/about_b $\mathrm{ca} /$ pdf/statsum.pdf, 2019-09-01/2020-04-25.

8. Lofquist, E. A., "The art of measuring nothing: The paradox of measuring safety in a changing civil aviation industry using traditional safety metrics". Safety Science, 48(10), 2010, pp.15201529.

9. Poll, D. I A., "21st-Century civil aviation: Is it on course or is it over-confident and complacent? thoughts on the conundrum of aviation and the environment". Aeronautical Journal, 121(1236), 2017, pp.115-140.

10. Liou, J. J. H., Yen, L., Tzeng, G. H., "Building an effective safety management system for airlines". Journal of Air Transport Management, 14(1), 2008, pp.20-26.

11. Du, H. B, Yuan, Y. F., Cui, X. Z, Yue, R. T., "Research on evaluation method of civil airport emergency management capability". Journal of Civil Aviation University of China, 35(3), 2017, pp.22-26.

12. Civil Aviation Administration of China. "The 13th Five-Year Plan for China's civil aviation development" [EB/OL]. Retrieved from http://www.caacnews.com.cn/1/1/201702/W020170216567988597 101.pdf, 2017-02-15/2020-04-25.

13. Mcmurtrie, K. J., Molesworth, B. R. C., "Australian flight crews' trust in voluntary reporting systems and just culture policies". Aviation Psychology \& Applied Human Factors, 8(1), 2018, pp.1121.

14. International Civil Aviation Organization. "Doc 9859: Safety Management Manual". Montreal: ICAO, 2018, Canada, pp.150154.

15. Federal Emergency Management Agency. "State capability assessment for readiness (CAR)". USA: FEMA, 2001

16. Haque, C. E., Sikder, M. S., "Events and failures are our only means for making policy changes: learning in disaster and emergency management policies in Manitoba, Canada". Natural Hazards, 98(1), 2019, pp.137-162.

17. Feldmann-Jensen, S., Jensen, S. J., Smith, S. M., Vigneaux, G., "The next generation core competencies for emergency management". Journal of Emergency Management, 17(1), 2019, pp.17-25.

18. Reichardt, U., Ulfarsson, G. F., Petursdottir, G., "Volcanic ash and aviation: recommendations to improve preparedness for extreme events". Transportation Research, 113(7), 2018, pp.101-113.

19. Martí Donati, A., "On-line coupling of volcanic ash and aerosols transport with global and regional meteorological models". Master thesis of Universitat Politècnica de Catalunya, Spain, 2017, pp.2537.

20. Xiong, S., Chen Z., Chang, J., Chin, K. S., "On extended power average operators for decision-making: A case study in emergency response plan selection of civil aviation". Computers \& Industrial Engineering, 130(4), 2019, pp.258-271.
21. Kajko-Mattsson, M., Nielsen, C., Winther, P., Vang, B., Petersen, A., "Eliciting CM3: emergency problem management at Scandinavian airline systems". Journal of Research and Practice in Information Technology, 38(4), 2006, pp.303-316.

22. Idrose, A. M., Adnan, W. A. W., Villa, G. F., Abdullah, A. H. A., "The use of classroom training and simulation in the training of medical responders for airport disaster". Emergency Medicine Journal, 24(1), 2007, pp.7-11.

23. Blackwell, B. F., Seamans, T. W., Esteban Fernández-Juricic, Devault, T. L., Outward, R. J., "Avian responses to aircraft in an airport environment”. The Journal of Wildlife Management, 83(4). 2019, pp.1-9.

24. Manley, M., Kim, Y. S., Christensen, K., Chen, A., “Airport emergency evacuation planning: an agent-based simulation study of dirty bomb scenarios". IEEE Transactions on Systems Man \& Cybernetics Systems, 46(10), 2017, pp.1390-1403.

25. Kahn, H., Wiener, A. J., "The Year 2000: A Framework for Speculation on the Next Thirty-Three Years". New York: The MIT Press, USA, 1967, pp.5-17.

26. Liu, Y. L., Chen Z. L., Wang J. "Large-scale natural disaster risk scenario analysis: a case study of Wenzhou City, China". Natural Hazards, 60(3), 2012, pp.1287-1298.

27. Zhang Y., Weng W. G., Huang Z. L., "A scenario-based model for earthquake emergency management effectiveness evaluation". Technological Forecasting and Social Change, 128(3), 2018, pp.197-207.

28. Liang, W. J., Cheng, M., "Scenario-Mission-Performance emergency model and case study of aircraft flight accidents". Safety and Environmental Engineering, 24(1), 2017, pp.146-151.

29. Wu, Q., Ren, F. Y., Guo, J., "Emergency rescue resources demand of civil airport based on scenario analysis". Journal of Civil Aviation, 2(6), 2018, pp.21-25.

30. Yang, L., Fan, Z. P., Yuan, Y., Li. H. Y., "A FTA-based method for risk decision-making in emergency response". Computers \& Operations Research, 42(2), 2014, pp.49-57.

31. Li, X., "Preliminary Exploration on Scenario-based Contingency Planning". Safety and Environmental Engineering, 18(2), 2011, pp.56-59.

32. Shu, Q. L., "Study on scenario evolvement and alternative generation of "scenario-response" decision-making in unconventional emergencies". Journal of University of Science and Technology of China, 42(11), 2012, pp.936-941.

33. Wu, Q., Tan, W., Gai, W. M., "Study on scenario analysis of civil aviation emergency based on dynamic Bayesian network". Journal of Safety Science and Technology, 12(03) 2016, pp.169-174.

34. Sheng, Y., Sun, Q. Y., Wang, Y. M., "Emergency scenario evolution and extraction method of key elements". Journal of Safety Science and Technology, 11(1), 2015, pp.17-21. 